\title{
The formaldehyde inspiration by the child patient, dentist, and dental assistant during formocresol pulpotomy
}

\author{
Kiyoshi Arai ${ }^{1, *}$, Akira Usui ${ }^{1}$, Junichiro Yoshioka ${ }^{2}$, Kazunori Hagiwara ${ }^{2}$, \\ Kensuke Matsune ${ }^{1}$, Ikuo Nasu ${ }^{3}$ and Takahide Maeda ${ }^{1}$ \\ ${ }^{1}$ Department of Pediatric Dentistry, Nihon University School of Dentistry at Matsudo \\ 2-870-1 Sakaecho-Nishi, Matsudo, Chiba 271-8587, JAPAN \\ 2 Nihon University Graduate School of Dentistry at Matsudo \\ 2-870-1 Sakaecho-Nishi, Matsudo, Chiba 271-8587, JAPAN \\ ${ }^{3}$ Department of Community Health Sciences, Nihon University School of Dentistry at Matsudo \\ 2-870-1 Sakaecho-Nishi, Matsudo, Chiba 271-8587, JAPAN
}

\begin{abstract}
Although using Buckley's Solution of formocresol (FC) in pulpotomy procedures is becoming less common in pediatric dentistry. This study measured concentrations of formaldehyde (FA) evaporated during fixing and investigated safe procedures for FC pulpotomy. Methods: Ten measurements were taken for each of the conditions described below. Locations measured for each condition were 1) at a position equivalent to the patient, 2) at a position equivalent to the dentist, and 3 ) at a position equivalent to the assistant dentist. Condition 1 used no peripheral equipment. Condition 2 used an intraoral air evacuator, Condition 3 used extraoral air evacuators, Condition 4 used both extraoral and intraoral air evacuators. At the patient's FA levels were $0.414 \mathrm{ppm}$ during Condition 1, $0.158 \mathrm{ppm}$ during Condition 2, $0.252 \mathrm{ppm}$ during Condition 3 , and $0.091 \mathrm{ppm}$ during Condition 4 . FA levels at the dentist were $0.115 \mathrm{ppm}$ during Condition 1, $0.042 \mathrm{ppm}$ during Condition 2, $0.081 \mathrm{ppm}$ during Condition 3, and $0.028 \mathrm{ppm}$ during Condition 4. FA levels at the dental assistant were $0.067 \mathrm{ppm}$ during Condition 1, 0.038 during Condition 2, $0.059 \mathrm{ppm}$ during Condition 3, and $0.025 \mathrm{ppm}$ during Condition 4. Exposure concentrations of FA during FC pulpotomy might have using of an extraoral, intraoral air evacuator during FC pulpotomy reduces formaldehyde exposure to patient, dentist, and dental assistant.
\end{abstract}

Key words Formaldehyde, Formocresol, Pulpotomy, Sick house syndrome

\section{Introduction}

Pulpotomy is performed in pediatric dental practice when caries progress to reversible pulpitis ${ }^{1,2}$. Reports show that dental pulp healing differs according to the agent applied to the pulp tissue during pulpotomy ${ }^{3,4)}$. Buckley's Solution of formocresol (FC) devitalizes the root pulp according to application time and concentration of formaldehyde. Maintaining healing radicular pulp tissue is an important outcome of an FC pulpotomy. Higher clinical rates of success are generally reported for pulpotomies conducted with

\footnotetext{
* Correspondence to: Kiyoshi Arai

E-mail: arai.kiyoshi@nihon-u.ac.jp

Received on March 8, 2011; Accepted on April 13, 2011
}

FC, compared to calcium hydroxide ${ }^{4-8)}$.

Formaldehyde (HCHO), an ingredient of FC, is colorless with a molecular weight of $30.03 \mathrm{Da}$, forms a combustible vapor with a strong odor, and becomes readily soluble in water, ethanol, and ether. Formaldehyde is widely used as an ingredient in a number of resins, as an embalming agent, and as a disinfectant. Formaldehyde and formulations that contain formaldehyde (up to 1\%) are designated as deleterious substances ${ }^{9}$. Formaldehyde is a gas at room temperature, but the gas readily converts to a variety of derivatives. One important derivative is the cycle compound trioxane, the "trimer" of formaldehyde with formula is $\left(\mathrm{CH}_{2} \mathrm{O}\right)_{3}$. When dissolved in water, formaldehyde converts to $\mathrm{H}_{2} \mathrm{C}(\mathrm{OH})_{2}$, a 


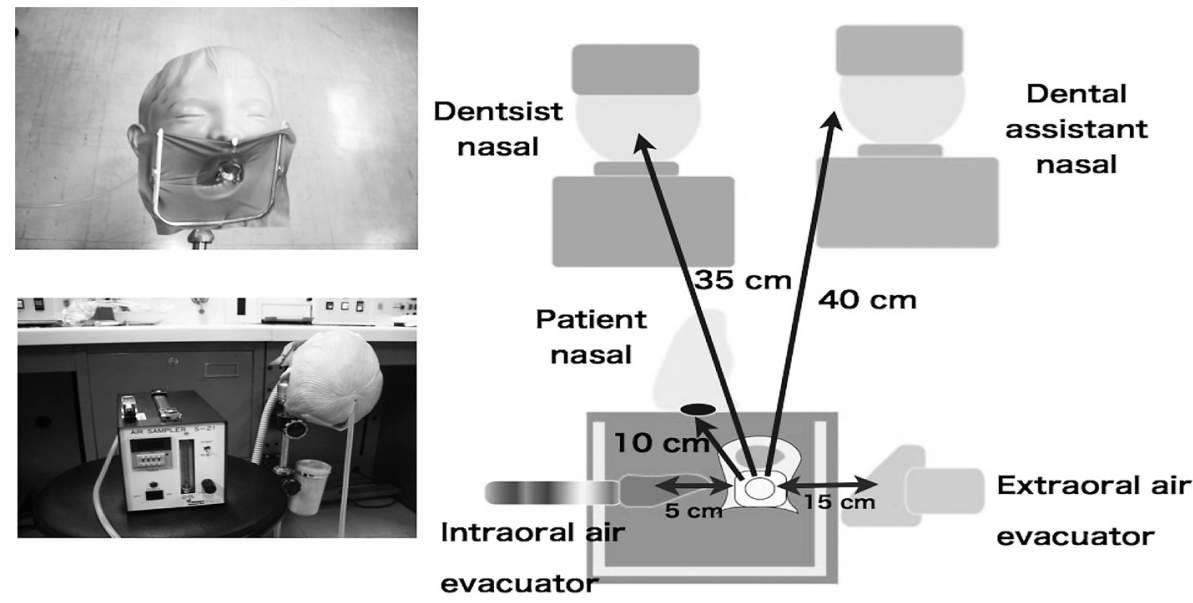

Fig. 1 Schematic of experiment

An experimental model assuming the pulpotomy of the lower left second primary molar with a pre-procedure placement of a rubber dam. Intoral air evacuator was provided $5 \mathrm{~cm}$. Extoral air evacuator was provided $15 \mathrm{~cm}$.

diol (i.e. a compound with two hydroxy groups). Aqueous solutions of formaldehyde are referred to as formalin ${ }^{10)}$. Formaldehyde is severely irritative and sensitizing to the skin mucosa, and causes protein fixing ${ }^{10)}$. The median lethal oral dose of formaldehyde $\left(\mathrm{LD}_{50}\right)$ in animals is 280 to $800 \mathrm{mg} / \mathrm{kg}$. Animal exposure to high concentrations of formaldehyde or oral administration of large quantities results in hemorrhage, edema and degeneration in the trachea and lungs, hyperemia, edema and necrosis in the lungs and kidneys, and cerebral edema and necrosis of the gangliocytes ${ }^{11)}$. Even exposure to low concentrations of formaldehyde can cause a severe irritation of the eyes and trachea, sneezing, coughing, and salivation. Levels of $5 \mathrm{ppm}$ can cause a mild irritation of the nose and throat and lacrimation in people who are unaccustomed to the chemical, while even people adjusted to the effects can stand no more than eight hours of continuous exposure at this level. Exposure to formaldehyde is not known to be a definite cause of chronic illness, although reports have found chronic obstructive ventilatory impairment in workers exposed to formaldehyde, and also sensitization of the skin and respiratory tract $^{12)}$. Contact dermatitis is a common occurrence during the manufacture of formaldehyde. A study in rats has shown a long term, repeated exposure to 6 to $15 \mathrm{ppm}$ formaldehyde causes squamous cell cancer, although these results have yet to be corroborated by epidemiological analysis of carcinogenicity in humans. Occupational Safety and Health Administration (OSHA) reported that the finding of nasal cancer in two strains of rats in three independent studies on formaldehyde alone to be extremely strong and reproducible evidence that formaldehyde is an animal carcinogen. Evidence of a dose-response relationship, finding cancers of identical cell-type and location in two species and evidence that formaldehyde is genotoxic strengthens the scientific relationship of formaldehyde exposure causing cancer ${ }^{13)}$. Formaldehyde is classified as "Group 1: Carcinogenic to humans," according to the International Agency for Research on Cancer (IARC) $)^{14,15}$. The American Conference of Governmental Hygienists (ACGIH) recommends a ceiling limit of worker exposure to formaldehyde of $0.3 \mathrm{ppm}^{16)}$, and the Japan Society for Occupational Health has set an acceptable concentration of $0.5 \mathrm{ppm}$ for workplace ${ }^{17}$.

This study measured the airborne concentration of formaldehyde during FC pulpotomy, for a onetime exposure and obtained findings that described methods for minimizing formaldehyde exposure, and for confirming the safety of the procedure.

\section{Materials and Methods}

An experimental model assuming the pulpotomy of the lower left second primary molar with a preprocedure placement of a rubber dam was undertaken in a mannequin used for pediatric dentistry training and a dental cast according to clinical operative procedures (Fig. 1). Each single procedure used $0.05 \mathrm{~m} l$ of the tissue fixing fluid included in Palpack 


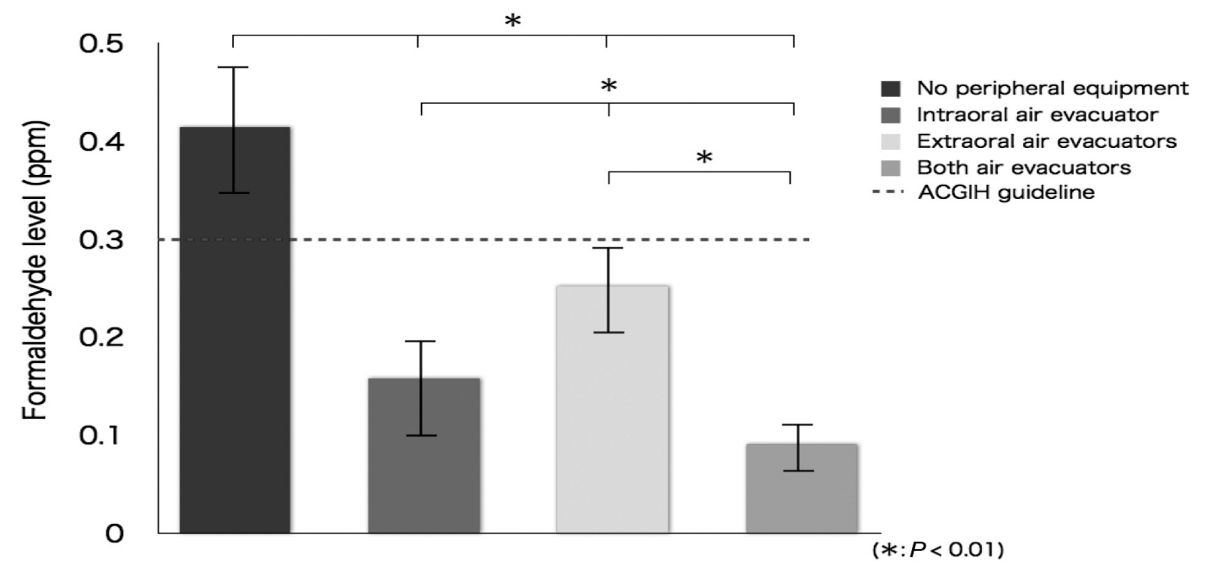

Fig. 2 Patient's nasal aperture formaldehyde levels

At the patient's nasal aperture formaldehyde levels were $0.414 \pm 0.085 \mathrm{ppm}$ during no peripheral equipment, $0.158 \pm 0.053 \mathrm{ppm}$ during intoral air evacuator, $0.252 \pm 0.038 \mathrm{ppm}$ during extoral air evacuator, and $0.091 \pm 0.012 \mathrm{ppm}$ during both extraoral and intraoral air evacuators. A significant difference was found between the conditions.

$\mathrm{V}^{\circledR}$ (Neo Dental Chemical Products). Palpack V ${ }^{\circledR}$ as Buckley's solution (each $100 \mathrm{ml}$ contains: $35 \mathrm{ml}$ cresol, $19 \mathrm{ml}$ formalin). On application of the swab soaked with the fixing fluid, a gas detector tube (Kitakawa Formaldehyde Detector Tube 713, Komyo Rikagaku Kogyo K.K.) and air sampler (S-21, Komyo Rikagaku Kogyo K.K.) were used to measure evaporated formaldehyde, with an air inflow of $350 \mathrm{~m} / /$ minute for ten minutes. This measurement repeated for 10 times. Before starting measurements, an air conditioning system was used to control the room at a temperature of $25^{\circ} \mathrm{C}$ (Ve-up II, Daikin Kogyo) and humidity of 35\% (KC-W45, Sharp).

\section{Measured locations}

Five measurements were taken for each of the conditions described below. Locations measured for each condition were 1) at a position equivalent to the nasal aperture of the patient mannequin $(10 \mathrm{~cm})$, 2) at a position equivalent to the nasal aperture of the dentist $(35 \mathrm{~cm})$, and 3$)$ at a position equivalent to the nasal aperture of the assistant dentist $(40 \mathrm{~cm})$. Each location was measured clinical position by ruler. Condition 1 used no peripheral equipment. Condition 2 used an intraoral air evacuator $\left(6.2 \mathrm{~m} / \mathrm{s} / \mathrm{cm}^{2}\right)$ during measurements, Condition 3 used extraoral air evacuators (extraoral aspiration device for dentist and assistant dentist) $\left(3.8 \mathrm{~m} / \mathrm{s} / \mathrm{cm}^{2}\right)$ during measurements, Condition 4 used both extraoral and intraoral air evacuators, and Background levels of formaldehyde were measured for complain the room before each measurement. A Kruskal-Wallis test was used to for comparing the exposure FA levels of each location for each condition.

\section{Results}

Background levels were measured for Conditions 1 to 4 before experiment for all condition background levels of FA were not defected. No significant difference was found between background readings at the four conditions. Figure 2 shows measurements obtained at a position equivalent to the nasal aperture of the patient. At the patient's nasal aperture formaldehyde levels were $0.414 \pm 0.085 \mathrm{ppm}$ during Condition 1, $0.158 \pm 0.053$ ppm during Condition 2, $0.252 \pm 0.038 \mathrm{ppm}$ during Condition 3, and 0.091 $\pm 0.012 \mathrm{ppm}$ during Condition 4. Figure 3 shows measurements obtained at a position equivalent to the nasal aperture of the dentist. Formaldehyde levels at the nasal aperture of the dentist were $0.115 \pm$ $0.018 \mathrm{ppm}$ during Condition 1, $0.042 \pm 0.025 \mathrm{ppm}$ during Condition 2, $0.081 \pm 0.038$ ppm during Condition 3, and $0.028 \pm 0.012 \mathrm{ppm}$ during Condition 4 . A significant difference was found between the conditions. Figure 4 shows measurements obtained at a position equivalent to the nasal aperture of the dental assistant. Formaldehyde levels at the nasal aperture of the dental assistant were $0.067 \pm 0.015 \mathrm{ppm}$ during Condition 1, $0.038 \pm 0.012$ ppm during Condition 2, $0.059 \pm 0.012 \mathrm{ppm}$ during Condition 3, and $0.025 \pm 0.019 \mathrm{ppm}$ during Condition 4. Significant 


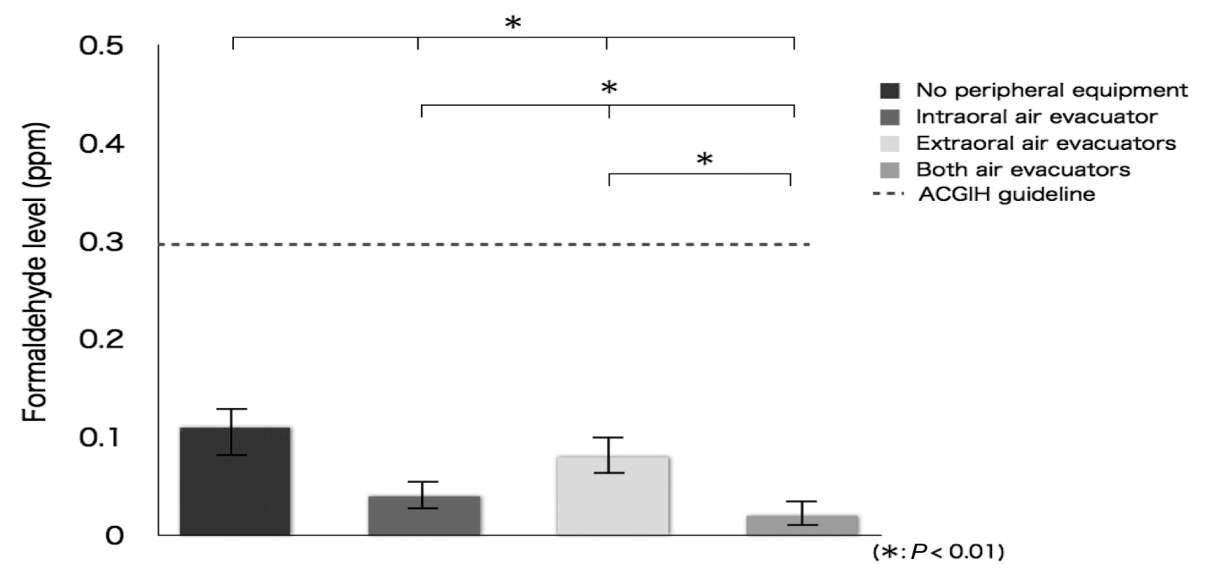

Fig. 3 Dentist nasal aperture formaldehyde levels

At the nasal aperture of the dentist formaldehyde levels were $0.115 \pm 0.018 \mathrm{ppm}$ during no peripheral equipment, $0.042 \pm 0.025 \mathrm{ppm}$ during intoral air evacuator, $0.081 \pm 0.038 \mathrm{ppm}$ during extoral air evacuator, and $0.028 \pm 0.012 \mathrm{ppm}$ during both extraoral and intraoral air evacuators. A significant difference was found between the conditions.

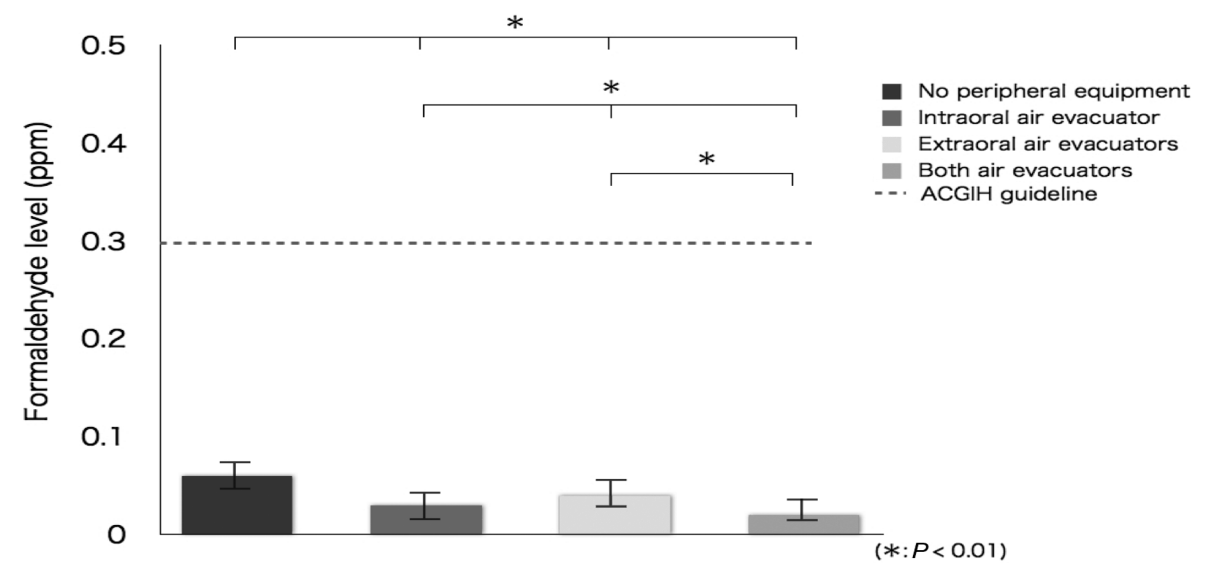

Fig. 4 Dental assistant nasal aperture formaldehyde levels

At the nasal aperture of the dental assistant formaldehyde levels were $0.067 \pm 0.015 \mathrm{ppm}$ during no peripheral equipment, $0.038 \pm 0.012 \mathrm{ppm}$ during intoral air evacuator, $0.059 \pm 0.012 \mathrm{ppm}$ during extoral air evacuator, and $0.025 \pm 0.019 \mathrm{ppm}$ during extraoral and intraoral air evacuators. A significant differences were found between the conditions.

differences were found between the conditions.

\section{Discussion}

Pulpotomy is a popular procedure that is performed on a daily basis for cases of primary molar caries. In clinical practice, both pulp capping and vital pulpotomy are widely performed on primary teeth affected by caries that cause dental pulp exposure and localized pulpitis ${ }^{1,2)}$.

Buckley's Solution of formocresol (FC) devital- izes the root pulp according to application time and concentration of formaldehyde. Maintaining healing radicular pulp tissue is an important outcome of an FC pulpotomy. Higher clinical rates of success are generally reported for pulpotomies conducted with FC, compared to calcium hydroxide ${ }^{4-8)}$.

Allowing the exposed dental pulp to create the hard dentin tissue needed to cover itself is the ideal outcome of treatment. Pulp capping, which is a method of placing a preparation consisting mainly of calcium hydroxide in contact with the 
pulp tissue to stimulate hard dentin tissue formation, and pulpotomy, are both common methods used in current clinical practice ${ }^{3)}$. A high $\mathrm{pH}$ of calcium hydroxide forms a necrotic layer of pulp tissue, promoting the ability of the pulp tissue to form hard tissue in the layer immediately below ${ }^{4}$. Long periods of highly alkali conditions inside the dentin can cause persistent problems and necrosis of the pulp tissue surface, and prevent the acquisition of protective activity. This leads to inflammation even with a minor bacterial invasion, and in a significant number of patients, the lack of anti-inflammatory action leads to pulpectomy. In recent years, there has been research into highly biocompatible pulp capping materials and methods that are minimally irritating to pulp tissue, such as mineral trioxide aggregate ${ }^{18,19)}$, ceramics $^{3)}$, calcium carbonate ${ }^{20)}$, lasers ${ }^{21)}$. FC pulpotomies in primary teeth are reported to achieve high rates of clinical success ${ }^{1)}$.

This study measured concentrations of formaldehyde in the air during FC pulpotomy, and gained insights into methods for minimizing formaldehyde exposure and confirming the safety of the procedure. The acute toxicity of formaldehyde raises concerns over its effect on the human body, particularly its irritant effect on the mucous membranes, and more recently, suspicion over its role in causing sick house syndrome when used in building materials ${ }^{22}$. Use of formaldehyde-containing compounds is common in endodontic treatment of adults, and there are reports of allergy to preparations that contain $\mathrm{FC}^{23,24)}$. Occupational exposure to formaldehyde causes irritation of the upper respiratory tract and asthmatic responses have been noted. A report ${ }^{25}$ ) also states the asthma-like symptoms caused by formaldehyde are not dependent on immunological mechanisms of activity.

According to $\mathrm{Kramps}^{26)}$, formaldehyde-specific IgE could not be detected in 85 out of 86 people with opportunities for exposure to formaldehyde, with no IgE-mediated allergy symptoms reported. According to Salkie ${ }^{27}$, testing of 63 medical pathologists identified for high occupational exposure to formaldehyde by questionnaire ( 23 were also allergic to formaldehyde) detected no IgE antibodies for formaldehyde in any person. The likelihood that formaldehyde induces an allergic response mediated by formaldehyde-specific IgE is believed to be extremely low $^{28)}$. Formaldehyde appears to be capable of binding to DNA, a well known mechanism by which chemicals cause cancer. Formaldehyde appears to be both an initiator and a late stage cancer causing chemical $^{29)}$.

Transdermal exposure to formaldehyde occurs with the patch test with a $1 \%$ to $2 \%$ aqueous solution of formaldehyde, while patients who exhibit hypersensitivity dermatitis have been reported as having reactions to a $0.003 \%$ aqueous solution of formaldehyde ${ }^{26)}$. Patch test results have suggested the involvement of cellular immunity in formaldehyde exposure. The International Agency for Research on Cancer (IARC) has classified formaldehyde as Group 1 for carcinogenicity, IARC reported that formaldehyde is reasonably anticipated to be a human carcinogen based on limited evidence of carcinogenicity in human and sufficient evidence of carcinogenicity in experimental animals $\mathrm{s}^{30)}$. Cohort studies of emblers and other professional that use formaldehyde showed some excess risk of the nasal and brain canser ${ }^{14)}$. The American Conference of Governmental Hygienists (ACGIH) recommends a ceiling limit for worker exposure of $0.3 \mathrm{ppm}^{16)}$, and The Japan Society for Occupational Health sets an acceptable concentration of $0.5 \mathrm{ppm}$ for the workplace ${ }^{31}$. Compared to the WHO guideline value of $0.08 \mathrm{ppm}$ for indoor air formaldehyde concentration in general indoor environments ${ }^{32)}$, it has been suggested that, during FC pulpotomy, children are potentially exposed to these levels for a period of just five minutes. Results of the experiments undertaken by this study show that when local ventilation was not performed, formaldehyde values for the child patient as well as the dentist and assistant dentist became close to concentrations that cause discomfort ( 0.04 to $0.24 \mathrm{ppm}$ ), according to the measurement of International Program of Chemical Safety (IPCS) ${ }^{33)}$. This study suggests that exposure to the concentrations of formaldehyde present during FC pulpotomy will cause feelings of discomfort but no subjective symptoms in the child, and carry a potential risk of formaldehyde exposure for the dentist and assistant dentist, depending on air direction, temperature and humidity in the examination room. The rubber dam is obligatory during the pulpotomy procedure in pediatric dentistry. Pulpotomy without a rubber dam increases the possibility of contamination of pulp and damage to the surrounding tissue from formaldehyde and irrigation solution. Rats administered formaldehyde in drinking water had increased incidences of forestomach papilomas in one study and leukemia and gastrointestinal tract tumors in anothers ${ }^{15)}$. 
Results also show that use of local ventilation (unitattached intraoral air evacuation $6.2 \mathrm{~m} / \mathrm{s} / \mathrm{cm}^{2}$ ) and extraoral aspiration equipment for the dentist and assistant dentist $\left(3.8 \mathrm{~m} / \mathrm{s} / \mathrm{cm}^{2}\right)$ during fixing with FC allow existing dental equipment to be used effectively in reducing airborne concentrations of formaldehyde. Increasing formaldehyde concentrations with increasing temperature also point to the importance of active ventilation, temperature and humidity control in the examination room during FC pulpotomies.

\section{Conclusions}

Based on this study's results, the following conclusions can be made:

1. Using of an extraoral or intraoral air evacuator during fixing of FC pulpotomy reduces formaldehyde exposure to patient, dentist, and dental assistant.

2. FC pulpotomy introduced concerns regarding exposure of the child's nasal mucosa to formaldehyde.

Increasing formaldehyde concentrations with increasing temperature also point to the importance of active ventilation, temperature and humidity control in the examination room during FC pulpotomies.

\section{Acknowledgments}

This works was supported by Grant-in-Aid for Scientific Research (B) 20791592.

\section{References}

1) Fuks, A. and Bimstein, E.: Clinical evaluation of diluted formocresol pulpotomies in primary teeth of school children. Pediatr Dent 3: 321-324, 1981.

2) Mejáre, I.: Pulpotomy of primary molar with coronal or total pulpitis using formocresol technique. Scand J Den Res 84: 29-36, 1976.

3) Okamoto, H., Arai, K., Matsune, K. et al.: The usefulness of new hydroxyapatite as a pulp capping agent in rat molars. Int J Oral-Med Sci 5: 50-56, 2006.

4) American Academy of Pediatric Dentistry: Guideline on pulp therapy for primary and immature permanent teeth. Pediatr Dent 31: 179-186, 2009.

5) Law, D.B.: An evaluation of vital pulpotomy technique. J Dent Child 23: 40-44, 1956.

6) Rölling, I. and Thylstrup, A.: 3-year clinical followup study of pulpotomized primary molars treated with the formocresol technique. Scand J Den Res 83 : 47-53, 1975.

7) Schröder, U.: Agreement between clinical and his- tologic findings in chronic pulpitis in primary teeth. Scand J Den Res 85: 583-587, 1977.

8) Via, F.W.: Evaluation of deciduous molar treated by pulpotomy and calcium hydroxide. J Am Dent Assoc 50: $34-43,1955$.

9) U.S. Department of Health and Human Services, Public Health Service, National Toxicology Program: 11th Report on Carcinogens. Available at "http://ntp. niehs.nih.gov/ntp/roc/eleventh/profiles/s089form. pdf", (Accessed Jun 4, 2010).

10) U.S. Environmental Protection Agency, Office Air and Radiation: Report to Congress on Indoor Air Quality, An Update on Formaldehyde. Available at "http://www.cpsc.gov/cpscpub/pubs/725.pdf", (Accessed Jun 4, 2010).

11) Meggs, W.J., Dunn, K.A., Bloch, R.M. et al.: Prevalence and nature allergy and chemical sensitivity in a general population. Arch Environ Health 51: 275282, 1996.

12) Gibson, P.R., Elms, A.N. and Ruding, L.A.: Perceived treatment efficacy for conventional and alternative therapies reported by persons with multiple chemical sensitivity. Environ Health Perspect 111: 1498-1504, 2003.

13) Occupation Safety and Health Administration (OSHA): Occupational exposure to formaldehyde; OSHA Fact Sheet, Jan 1, 1995.

14) IARC Monographs on the Evaluation of Carcinogenic Risks to Humans 82, Lyon, WHO, 2006.

15) IARC Monographs on the Evaluation of Carcinogenic Risk of Chemicals to Humans, Wood Dust and Formaldehyde. International Agency for Research on Cancer 62, France, 1995.

16) American Conference of Government Industrial Hygienists (ACGIH): Notice of intended charge Formaldehyde. Appl Occup Environ Hyg 7: 852-874, 1992.

17) Ministry of Health, Labour and Welfare Report (2007): Chapter 3. Realizing fair and diverse work styles and securing the safety of workers. Section 2. Creating safe and secure workplaces. (online), Available at "http://www.mhlw.go.jp/english/wp/wp-hw2/part2/ p2c3s2.pdf", (Accessed Jan 4, 2009).

18) Trabinejad, M., Watson, T.F. and Pitt Ford, T.R.: Sealing ability of a mineral trioxide aggregate when used as a root end filling material. J Endod 19: 591595, 1993.

19) Faraco, I.M. Jr. and Holland, R.: Response of the pulp of dogs to capping with mineral trioxide aggregate or a calcium hydroxide cement. Dent Traumatol 17: 163-166, 2001.

20) Lu, P., Arai, K. and Kuboyama, N.: Possibility of application of calcium carbonate in pulpotomy of rat molars. Ped Dent J 20: 45-56, 2010.

21) Yang, J., Osuga, N., Li, X. et al.: Observations of pulpotomy in rats using in vivo Micro-CT - The changes after treatment of formocresol and calcium hydroxide pulpotomies or $\mathrm{CO}_{2}$ laser irradiation - . Ped Dent J 17: 32-39, 2007.

22) Miller, C.S. and Prihoda, T.J.: The Environmental 
Exposure and Sensitivity Inventory (EESI): a standardized approach for research and clinical applications. Toxicol Ind Health 5: 370-385, 1991.

23) Ebner, H. and Kraft, D.: Formaldehyde-induced anaphylaxis after dental treatment? Contact Dermat 24: 307-308, 1991.

24) El Sayed, F., Seite-Belleza, D., Sans, B. et al.: Contact Urticaria from formaldehyde in a root canal dental paste. Contact Dermat 33: 353, 1995.

25) Kim, C.W., Song, J.S., Ahn, Y.S. et al.: Occupational asthma due to formaldehyde. Yonsei Med J 42: 440445, 2001.

26) Kramps, J.A., Peltenberg, L.T.C., Kerklaan, P.R.M. et al:: Measurement of specific IgE antibodies in individuals exposed to formaldehyde. Clin Exp Allegy 19: 509-514. 1989.

27) Salkie, M.L.: Allergens in the workplace. Clin Biochem 27: 81-85, 1994.

28) Dykewicz, M.S., Patterson, R., Cugugell, D.W. et al.: Serum $\operatorname{IgE}$ and $\operatorname{IgG}$ to formaldehyde-human serum albumin lack of relation to gaseous formaldehyde exposure and symptoms. J Allergy Clin Immunol 87: 48-57, 1991.

29) Burge, P.S., Harris, M.G., Lam, W.K. et al.: Occupation asthma due to formaldehyde. Thorax 40: 255260, 1985.

30) IARC Monographs on the Evaluation of Carcinogenic Risk of Chemicals to Humans, Some Industrial Chemicals and Dyestuffs. International Agency for Research on Cancer 29, France, 1982.

31) The Japan Society for Occupation Health: Recommendation of occupational exposure limits (20072008). J Occup Health 49: 328-344, 2007.

32) World Health Organization (Regional Office for Europe): WHO Air Quality Guidelines. 2nd ed., 2001.

33) International Program on Chemical Safety (IPCS): Environmental Health Criteria 89, Formaldehyde. (online), Available at "http://www.inchem.org/documents/ehc/ ehc/ehc89.htm", (Accessed Jan 4, 2009). 